Recebido: 10/11/2015

Aprovado: 02/06/2016

\title{
O processo de urbanização da cidade de São Paulo e o Movimento Popular de Arte em São Miguel Paulista
}

Valdemir Camargo Bueno*

\begin{abstract}
Resumo: Ao longo da história da cidade de São Paulo, surgem formas de resistência popular impulsionadas por movimentos sociais que combatem o modelo de produção do espaço dessa cidade. Dentre seus bairros mais periféricos destaca-se São Miguel Paulista, bairro operário situado no extremo leste da zona leste da cidade. O bairro, a partir da década de 1930, passou por um vigoroso processo de urbanização, promovido pela industrialização e pela migração de paulistas, paranaenses e, sobretudo, baianos. Nesse processo histórico, desponta, no final da década de 1970, a partir de um enfrentamento ocorrido entre artistas locais, a prefeitura e a igreja, em torno do direito de uso e ocupação de uma pequena capela jesuítica, o Movimento Popular de Arte (MPA) de São Miguel Paulista, cuja atuação é significativa quanto à representação do cotidiano dos seus moradores e, quanto ao papel da cultura como ação política
\end{abstract}

Palavras-Chave: Industrialização e Urbanização; Migrações Regionais; Cultura e Política.

Abstract: Throughout the history of the city of São Paulo, there are forms of popular resistance driven by social movements that fight the productive model of the space in this town. Among their more peripheral areas stands São Miguel Paulista, a worker's class neighborhood situated at the eastern end of the East side of the city. The neighborhood, from the 1930s, went through a vigorous process of urbanization, promoted by industrialization and migrants that came from the states of São Paulo, Parana and, above all, Bahia. In this historical process, stands out in the late 1970s, from a confrontation that occurred between local artists, the Town Hall and the Church, about the right of use and occupation of a small Jesuit Chapel, the Popular Movement (MPA) of São Miguel Paulista, whose performance is significant as the representation of the daily life of its residents, and the role of culture as a political action.

Keywords: Industrialization and urbanization; Regional Migration; Culture and Politic.

\footnotetext{
Mestrando do Programa de Pós Graduação em História e Sociedade na Universidade Estadual Paulista (UNESP), campus Assis. O trabalho que originou este artigo foi apresentado na Semana de História de Assis, em 2014.
} 


\section{A urbanização brasileira e a cidade de São Paulo}

Durante três séculos, a urbanização brasileira ocorreu de forma lenta e muito limitada pelo poder do campo. As cidades brasileiras representaram, entre os séculos XVI e XVIII, o desejo longínquo do poder metropolitano de estabelecer e manter o controle políticoadministrativo sobre o território da colônia por meio do sistema de capitanias e do governo geral. De acordo com Santos ${ }^{1}$ no âmbito municipal, as funções administrativas, religiosas, jurídicas e comerciais, durante nossa história colonial, representaram o poder que emanou do campo.

Ao estudar o período entre 1520 e 1720 , Nestor Goulart Reis Filho ${ }^{2}$ destaca três etapas da organização urbana do território brasileiro. A primeira, entre 1530 e 1570, com ênfase no intervalo entre 1530 e 1540 e o ano de 1567, data da fundação da cidade do Rio de Janeiro. A segunda etapa, que se estende de 1580 a 1640, quando são constituídas dez vilas e três cidades, sobressaindo-se a fundação da cidade de Filipéia da Paraíba, atual João Pessoa, em 1585. Na terceira etapa, entre 1650 e 1720, são fundadas 35 vilas, sendo duas delas alçadas à categoria de cidades: Olinda e São Paulo. Ao fim do período, a rede urbana brasileira está constituída por um respeitável conjunto de sessenta e três vilas e oito cidades.

Durante cerca de um século, nas décadas posteriores à terceira etapa do processo de urbanização do Brasil, as mudanças representadas pelo início da tecnicização do território, entre 1720 e 1815, não são capazes de modificar a estrutura sócio-política daquilo que Bastide $^{3}$ denomina como a "civilização do açúcar", fundada no poder do latifúndio e da monocultura, que assim permanece até o final do século XIX. Somente a partir de 1872, quando o engenho é substituído pela usina, a primazia do capital nacional oriundo da terra é submetida ao poder do capital financeiro internacional, e a ele se associa. Como assinala Warren Dean ${ }^{4}$, as cidades brasileiras se desenvolvem como consequência de um capital agrário e comercial agregado ao capital estrangeiro.

Essa transformação financeira na estrutura de produção, introduzida na economia brasileira pela expansão cafeeira no estado de São Paulo, o término do binômio escravidãomonarquia, no âmbito nacional, nos termos de Bastide $^{5}$, faz com que a urbanização se

\footnotetext{
${ }^{1}$ SANTOS, Milton. A Urbanização Brasileira. São Paulo: Editora da Universidade de São Paulo, 2009, pág. 21.

${ }^{2}$ Apud SANTOS, Milton. A Urbanização Brasileira. São Paulo: Editora da Universidade de São Paulo, 2009, pág. 21.

${ }^{3}$ BASTIDE, Roger. Brasil, Terra de Contrastes. São Paulo: Difel, 1978, p. 56-57.

${ }^{4}$ Apud LANNA, Ana Lúcia Duarte. Uma cidade na transição Santos: 1870-1913. São Paulo-Santos: Editora Hucitec-Prefeitura Municipal de Santos, 1996, p. 18-19.

${ }^{5}$ BASTIDE, loc. cit.
} 
desenvolva de forma mais acelerada e, aos poucos, a casa da cidade passa a ser mais importante do que a sede da fazenda. A partir da segunda metade do século XIX, movido pelo avanço da economia cafeeira e pela industrialização, o estado de São Paulo assume a dianteira desse processo, promovendo um movimento de urbanização que envolve tanto o interior quanto o litoral do seu território, alimentado por capitais mercantis e caracterizado pela implantação de novos meios técnicos. A malha ferroviária, as melhorias da estrutura portuária e os novos meios de comunicação atribuem ao território paulista uma fluidez mais intensa, provocando uma maior complexidade na vida de relações e tornando mais diversas as atividades produtivas de caráter urbano, tais como o comércio e a prestação de serviços. No entanto, para Santos ${ }^{6}$, é somente a partir da segunda metade do século XX, em virtude da industrialização associada à precariedade das condições de vida no campo, que a urbanização brasileira se desenvolve de fato e adquire as características que conhecemos hoje.

Desse modo, entre 1940 e 1960, ainda se observa um aumento menor da população urbana em relação ao crescimento da população total do país na década de 1960-1970, porém, ocorre um ponto de inflexão e de virada no processo, com a aproximação dos valores, para que, na década seguinte, 1970-1980, o crescimento da população urbana em termos numéricos seja maior que o da população rural e que o da taxa média de crescimento da população absoluta do país.

Essa tendência, verificada no período, marca a redistribuição das classes médias e pobres no território e as cidades maiores são as que absorvem os maiores contingentes migratórios de trabalhadores pobres. Desse modo, a cidade de São Paulo, segundo Santos ${ }^{7}$ é aquela que apresenta o maior poder de atração e, entre 1970 e 1980, absorve 17,37\% do total de migrantes do país.

\section{Urbanização e formação da classe operária}

Ao analisar a expansão urbana da cidade de São Paulo, Jorge ${ }^{8}$ demonstra o desenvolvimento de uma urbanização elitista e especulativa, inserida num amplo contexto de intensificação das relações capitalistas na sociedade brasileira, decorrente da assimilação dos novos meios técnicos e científicos, o que promove a formação de uma grande cidade descontínua, alternando as funções de grande centro urbano com características semi-

\footnotetext{
${ }^{6}$ Ibidem, 2009, p. 30.

${ }^{7}$ Ibidem, 2009, pág. 65.

${ }^{8}$ JORGE, Janes. Tietê, o rio que a cidade perdeu: São Paulo 1890-1940. São Paulo: Alameda, 2006. 
capitalistas de povoados de roça e modo de vida sertanejo. O planejamento das obras, a legislação urbanística e a coerção constituem-se como mecanismos de segregação social que conferem espaços geográficos diferentes para os trabalhadores pobres e suas famílias e para as classes média e alta.

Considerando como classe operária, todos os trabalhadores desprovidos de propriedade ou de qualquer fonte de renda, que, para poder viver, vendem sua força de trabalho, não se considerando, portanto, apenas os operários de fábrica, para sua conceituação, mas, todo um conjunto de assalariados que inclui também os trabalhadores rurais e os prestadores dos mais diversos tipos de serviços. Essa condição de inexistência da propriedade dos meios de produção para a maioria dos trabalhadores, e sua consequente condição de proletariado, é fruto do processo de desenvolvimento histórico do sistema capitalista, que tem início com o cercamento de terras, os enclosures na Europa, mais especificamente na GrãBretanha, como analisado por Marx ${ }^{9}$ no capítulo "A acumulação primitiva", e a expulsão, que se intensifica com a industrialização, dos camponeses para as cidades. Mas não é só isso, passa também pela criação cultural de uma predisposição, como afirma Marx ${ }^{10}$

Não basta que as condições de trabalho apareçam num polo como capital e no outro polo pessoas que nada tem para vender a não ser sua força de trabalho. Não basta também forçarem-nas a se vender voluntariamente. Na evolução da produção capitalista, desenvolve-se uma classe trabalhadora que, por educação, tradição, costume, reconhece as exigências daquele modo de produção como leis naturais, evidentes.

Durante séculos a classe dominante disciplina a vida de milhares de camponeses expulsos de suas terras e aldeias, persegue a ferro e fogo todo aquele que se recusa a aceitar a venda de sua força de trabalho e cria o estereótipo do vagabundo. Ao analisar a documentação relativa à Lei Negra, Thompson (1987) observa que se trata de um exemplo de forma legal de coerção exercida pelo Estado em favor do capital, concluindo que, de acordo com essa legislação, os crimes dos camponeses não são contra a pessoa, porém, contra a propriedade privada, como aponta Silva ${ }^{11}$.

\footnotetext{
${ }^{9}$ Apud SILVA, Maria Aparecida de Moraes. Errantes do Fim do Século: São Paulo: Fundação Editora da UNESP, 1999, p. 29.

${ }^{10}$ Apud SINGER, Paul. A formação da classe operária: Editora da Universidade Estadual de Campinas,1987, p. 22.

${ }^{11}$ Apud SILVA, Maria Aparecida de Moraes. Errantes do fim do século: São Paulo: Fundação Editora da UNESP, 1999, p. 28-29.
} 
De acordo com Singer ${ }^{12}$, as cidades que passam a se desenvolver intensamente, a partir dos cercamentos de terras e do desenvolvimento do comércio, são, enquanto pequenas e pobres, mais igualitárias e democráticas, e, à medida que se tornam grandes e ricas, passam a ser desiguais e dominadas pelos ricos. Enquanto isso ocorre, a perda do direito à terra, da propriedade das ferramentas e da liberdade de criação, proporcionada pela atividade artesanal que foi transformada pela concentração do capital, e pelo desenvolvimento tecnológico da produção, dá início a formação da classe operária.

As metrópoles do século XIX causam em seus observadores um misto de paixão e repulsa, pois, ao mesmo tempo em que elas exibem todas as conquistas e possibilidades proporcionadas pelo desenvolvimento tecnológico, elas também deixam transparecer a crescente atomização da sociedade em nome do individualismo e do egoísmo.

Após percorrer as ruas de Londres em meados da década de 1840, Engels ${ }^{13}$ descreve a divisão de classes que já caracteriza a ocupação espacial da cidade e indica a situação de penúria em que vive a classe operária: “[...] não há um único vidro de janela intacto, os muros são leprosos, os batentes das portas e janelas estão quebrados, e as portas, quando existem, são feitas de pranchas quebradas”. Se nos países de industrialização mais antiga, a condição de vida da classe operária era esta, nos países de industrialização mais recente a formação da classe operária, guardadas as particularidades históricas de cada caso, também se deu a partir de transformações ocorridas nas estruturas de produção e fundiária do campo, concomitantemente à transferência da população para as cidades e a expansão física das mesmas.

Segundo Dean ${ }^{14}$, no Brasil, a formação da classe operária surge ainda antes da Abolição com a criação das usinas de açúcar que a precedem e que adotam o trabalho assalariado ao lado de um semi-proletariado rural caracterizado pelos ex-escravos "moradores" das plantações do Nordeste e pelos colonos paulistas de origem imigrante. Nas cidades, a substituição dos escravos por trabalhadores livres também contribui para a formação da classe operária urbana. Esta situação ambígua, na qual o senhor passa a pagar pelo trabalho do escravo, os coloca em pé de igualdade, pois, só se paga salário para trabalhadores livres. De acordo com Dean ${ }^{15}$, é imprescindível que o senhor veja no escravo

\footnotetext{
${ }^{12}$ SINGER, Paul. A formação da classe operária: Editora da Universidade de Campinas, 1987, p. 20.

${ }^{13}$ Apud BRESCIANI, Maria Stella. Londres e Paris no século XIX: o espetáculo da pobreza. São Paulo: Brasiliense, 2004, p. 23-25.

${ }^{14}$ DEAN, Warren. A Industrialização de São Paulo (1880-1945). Tradução Difel, 1971, p. 126.

${ }^{15}$ Ibidem, 1971, pág. 126.
} 
um ser inferior, destituído de humanidade, pois, no Brasil, dos anos 1870-1880, esta condição estava desaparecendo.

A formação do proletariado brasileiro entra em seu estágio decisivo entre 1880 e 1920 , com a crescente necessidade de mão de obra causada pela intensificação das atividades econômicas e pela escassez da força de trabalho escrava, que é contornada com a imigração europeia, já sob o regime de trabalho assalariado. Na realidade não cresce apenas o operariado industrial, uma vez que a industrialização ainda se encontra em estágio incipiente, mas, toda uma gama de trabalhadores ligados aos setores de transporte, construção civil e serviços, condicionados pela financeirização da atividade cafeeira que transfere do campo para a cidade a dinâmica da economia. Entre 1920 e 1940, o avanço da participação do operariado na população economicamente ativa passa de $8,2 \%$ para $14,8 \%$, porém, em sua maioria, são constituídos por trabalhadores da prestação de serviços e não da indústria propriamente dita. Portanto, ocorre uma evolução da população assalariada urbana geral, constituindo um modelo de proletariado mais amplo em relação a definição clássica desse conceito.

É nesse contexto que, a partir dos anos 1940, a industrialização e a formação da classe operária brasileira iniciam um novo estágio, com a instalação de grandes indústrias, em sua maioria multinacionais voltadas para a produção de bens intermediários, de consumo e de bens de capital. Se até os anos 1930, ainda que tenham ocorrido, a urbanização e a industrialização ocorrem de acordo com o desenvolvimento do capitalismo subordinado aos interesses do campo, desde então a cidade passa a definir os rumos da economia e da sociedade do país. Com isso, a economia brasileira começa a apresentar uma crescente necessidade de mão de obra assalariada urbana que faz com que, entre 1940 e 1980, a parcela ocupada na agricultura passe de $64,4 \%$ para $40,8 \%$, respectivamente, do total da população economicamente ativa.

Portanto, com a real transformação da economia brasileira da condição de primárioexportadora para a condição urbano-industrial ocorrida no período posterior aos anos 1930, a proletarização do homem do campo dá-se por uma combinação de expropriação direta dos posseiros e de empobrecimento gradual de pequenos proprietários rurais. Ao longo desses anos, juntamente com a expropriação dos camponeses ocorre o processo de mecanização das lavouras que expulsa milhões de trabalhadores rurais que se veem obrigados a migrar para as cidades em busca de trabalho. Nas grandes metrópoles industriais brasileiras que se formam ao longo das décadas do pós-guerra, como São Paulo, o destino da maioria dos migrantes vindos do campo são os loteamentos populares dos bairros da periferia mais distante 
desprovida de recursos e onde os mesmos podem, com seus parcos salários, adquirir um terreno ou arcar com os preços dos aluguéis.

\section{Industrialização e urbanização do bairro de São Miguel Paulista}

Sendo assim, a partir das três primeiras décadas do século XX a cidade de São Paulo passou a apresentar um rápido crescimento populacional e, com isso, algumas áreas rurais localizadas no então distrito de São Miguel foram ocupadas por portugueses e japoneses que montaram chácaras para o cultivo de flores, frutas e hortaliças, cuja produção abastecia a cidade de São Paulo. Ainda na primeira metade do século XX, de acordo com Jorge ${ }^{16}$, as olarias foram proibidas de se instalar nos arredores urbanos da cidade e tenderam a se localizar nas "várzeas de rio acima" entre Penha e Guarulhos, anos depois chegando até as proximidades de Mogi das Cruzes. A produção de tijolos e telhas, realizada por olarias que exploravam areia e argila do leito do rio Tietê passou, então, a representar uma atividade econômica importante para os habitantes dos subúrbios orientais da cidade, entre eles o distrito de São Miguel. Na medida em que a cidade de São Paulo crescia e se desenvolvia, como destaca Fontes $^{17}$, a proximidade do rio Tietê era uma vantagem estratégica para o bairro, pois o rio era ao mesmo tempo, fonte de matérias primas, areia, argila, cascalho, necessárias à incipiente indústria local; e meio de transporte possibilitando que barcaças transportando a produção local navegassem rio abaixo até as proximidades da região central da cidade.

Nesse contexto, Fontes ${ }^{18}$ observa que o Distrito de São Miguel Paulista é um dos que mais crescem por conta dessas transformações. E, a partir da instalação da Companhia Industrial Nitro Química, inaugurada em 1935, empresa que se tornou uma das maiores do Brasil, o bairro se transforma em uma enorme comunidade operária formada por trabalhadores migrantes. Entre eles, destacam-se os nordestinos, ou seja, migrantes oriundos dos estados brasileiros que compõem a região geoadministrativa do Nordeste ${ }^{19}$, especialmente baianos, pernambucanos e paraibanos. Mas, os paulistas, mineiros e paranaenses também

\footnotetext{
${ }^{16}$ JORGE, Janes. Tietê, o rio que a cidade perdeu: São Paulo 1890-1940. São Paulo: Alameda, 2006, p. 57-58)

${ }^{17}$ FONTES. Paulo Roberto Ribeiro. Comunidade Operária, Migração Nordestina e Lutas Sociais: São Miguel Paulista (1945-1966). Campinas: Universidade Estadual de Campinas, 2002, p. 105.

${ }^{18}$ FONTES. Paulo Roberto Ribeiro. Comunidade Operária, Migração Nordestina e Lutas Sociais: São Miguel Paulista (1945-1966). Campinas: Universidade Estadual de Campinas, 2002.

${ }^{19}$ Vale lembrar que tais classificações se tratam, também, de categorias ideológicas que procuram construir o imaginário nacional, como afirma Durval Muniz de Albuquerque Jr. em: A Inversão do Nordeste e outras artes (1999, p. 307-311) “O Nordeste, assim como o Brasil, não são recortes naturais, políticos ou econômicos apenas, mas, principalmente, construções imagético-discursivas, constelações de sentidos”
} 
ajudaram a formar sua população. Valendo-se do momento histórico propício ocasionado pelos investimentos do Estado em infraestrutura e incentivos à indústria, assim como da entrada do país na Segunda Guerra Mundial, o bairro continua crescendo até a década de 1950. Nos anos 1960, no entanto, o bairro começa a perder importância como distrito industrial e passa a adquirir características de área dormitório para os trabalhadores da cidade. Contudo, os moradores de São Miguel Paulista continuaram a trabalhar nas indústrias e em outras atividades econômicas da cidade, fazendo com que o bairro não perdesse seu caráter de comunidade operária e carente.

De acordo com Fontes $^{20}$, a história do bairro paulistano de São Miguel foi alterada profundamente nos anos 30, quando ali se instalou a Companhia Nitro Química Brasileira. Embora tendo sua origem como aldeamento indígena e missão jesuítica nos séculos 16 e 17, sendo um dos mais antigos bairros da cidade de São Paulo, São Miguel Paulista pouco se desenvolvera até se aproximar a virada da primeira para a segunda metade do século $\mathrm{XX}$, tendo permanecido como um pequeno núcleo habitacional no extremo leste do município de São Paulo até aproximar-se a Segunda Guerra Mundial e a crescente demanda internacional por produtos químicos levasse o governo Vargas a promover uma intensa campanha de instalação de unidades industriais desse tipo no território nacional. Foi desse modo, com incentivos governamentais para aquisição de empréstimos, investimentos estatais na infraestrutura, inclusive ferroviária, e contando com a crescente demanda civil e militar, que as famílias Lafer e Ermírio de Moraes trouxeram, dos Estados Unidos, a Companhia Industrial Nitro Química, cujo principal produto produzido era o fio sintético raiom.

No pós-guerra, ao longo dos anos cinquenta e sessenta, a empresa se tornaria uma das maiores do Brasil e chegaria a empregar sete mil trabalhadores, e seus proprietários imaginavam transformá-la na maior indústria de base do país no setor químico. No entanto, por vários motivos, entre eles, a nova configuração geoestratégica mundial e a disputa política interna entre o setor ligado ao modelo nacional-desenvolvimentista de Getúlio Vargas e João Goulart, e o setor ligado ao modelo de substituição de importações associado ao capital estrangeiro, que culmina com o golpe civil-militar de 1964 e, ainda, a queda de preços do fio sintético de raiom no mercado mundial provocada pela concorrência de novos produtos similares mas, tecnologicamente superiores, tais planos fracassaram.

No final dos anos 1980, após passar por várias fases de reestruturação, a empresa ainda mantinha sua importância para o bairro não pela capacidade de geração de emprego e

${ }^{20}$ Ibidem, 2002, p. 105. 
produção, mas, pelo valor simbólico daquilo que ela representa para a história não somente do bairro de São Miguel, mas, também, para a cidade de São Paulo. Na transição vivida pelo bairro entre os anos 1970 e 1980, que passou da condição de um dos distritos industriais mais importantes e representativos de uma época, para a de bairro dormitório que abriga uma grande população trabalhadora, o crescimento populacional prosseguiu acelerado com a chegada de novos migrantes e de moradores da cidade que para esta região se transferiram em busca de condições mais acessíveis de moradia. Isso se deu mesmo sabendo implicações como piores condições de infraestrutura de saneamento básico, transporte, educação, lazer, esporte e cultura, juntamente com a crescente criminalização da população residente, sobretudo, os jovens.

Nesse contexto, a partir da segunda metade da década de 1970 surgiram movimentos sociais como, associações de amigos de bairro, de favela, de negros, de mulheres, por moradia, assim por diante, articulados às comunidades eclesiais de base da igreja Católica, ao "novo sindicalismo" de base católica e caráter negociador, que substituiu o sindicalismo da primeira metade do século XX, caracterizado pela influência do anarquismo e do partido comunista, que buscavam uma posição de confronto com o empresariado e o Estado, e aos remanescentes da esquerda clandestina. Esses movimentos sociais apontavam para o desejo de participação política da sociedade e para as reivindicações sociais em torno da luta pela melhoria das condições de vida da população, uma vez que o modelo desenvolvimentista associado ao capital estrangeiro adotado pelo governo militar, com o apoio das elites reacionárias, já apresentava os sinais de sua falência e o regime começava a delinear as bases da redemocratização tutelada do país.

\section{As vanguardas culturais nos anos de chumbo e o Movimento Popular de Arte de São Miguel Paulista}

O termo vanguarda tem sua origem no campo militar e se refere aos batalhões de exército que se deslocam à frente do corpo da tropa oferecendo ao exército inimigo o primeiro combate, buscando desbaratar sua estrutura de ordenamento e facilitar sua derrota. No campo da produção artístico-literária, de acordo com Poglioli ${ }^{21}$, o termo é empregado para definir o momento em que a arte assume o ethos revolucionário, transformando-se na definição que

\footnotetext{
${ }^{21}$ POGLIOLI, Renato. Teoria de la arte de vanguarda. Madri: Revista de Occidente, 1964.
} 
indica a ação política através da produção artística. A arte de vanguarda assume, assim, o papel de denúncia contra a sociedade técnico-burguesa, reconhecendo o valor de suas conquistas, mas sem deixar de apontar a falta de perspectiva dessa sociedade para além do produtivismo e do lucro.

No campo da teoria da arte, ocorre certa dificuldade para definir os movimentos de vanguardas artísticas, pois, por um lado, reconhece-se a importância desses movimentos para o desenvolvimento da arte moderna, mas, por outro, eles são vistos como demasiadamente ingênuos. Dessa forma, quando alguns os veem como o germe que dá origem a novos momentos do mundo das artes, outros o celebram pela improbabilidade de suas propostas quanto a viabilizar novos caminhos a serem trilhados pela sociedade e pelas artes. Quanto a isto, é possível imaginar que a verdadeira função da vanguarda não é estabelecer proposições viáveis de serem implantadas, mas provocar a dúvida e o questionamento, propondo o debate que leve ao surgimento de novas ideias e utopias.

O conceito de vanguarda é, então, algo que envolve a capacidade de entender a existência do artifício artístico vinculado à capacidade de interpretação dos aspectos da sociedade. Desse modo, vanguarda artística pode ser entendida como a consciência antipositivista da modernidade capitalista marcada pela transformação do tempo em um objeto mensurável e negociável, sustentada na concepção do progresso contínuo. Nesse sentido, pode-se dizer que existem duas modernidades: a estética e a burguesa. O poeta/literato observa e analisa a sociedade moderna materialista, apontando suas contradições e seus valores egoístas e individualistas. A arte de vanguarda combate a noção burguesa de sociedade que prega uma ideia abstrata de liberdade e humanismo que, associada à noção de fazer e obter resultados, procura instalar as bases morais do produtivismo e da técnica, sendo este o aspecto denunciado e, ao mesmo tempo, combatido pela modernidade estética na vanguarda.

Cabe salientar, aqui, que o ambiente artístico-literário brasileiro na virada dos anos 1960 para os anos 1970, e ao longo dessa década, observou o surgimento de diversas correntes artístico-literárias que travaram entre si um importante debate que envolveu, entre outros aspectos, questões em torno do conteúdo e da estética, bem como, quanto ao tipo de discurso que a arte e a cultura deveriam produzir no combate à ditadura civil-militar implantada em março de 1964, e ao caráter conservador e paternalista da modernização da sociedade brasileira que vinha sendo consolidado, na base da brutalidade, tortura e assassinato, nos porões da repressão. Dentre elas destaca-se a arte engajada do CPC (Centro

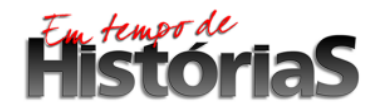


Popular de Cultura), a Poesia Concreta, a Tropicália e a Poesia Marginal. Nesse ambiente, formado por jovens poetas, geralmente universitário e que contavam com poucos recursos financeiros e técnicos para a realização e divulgação de sua arte, sobressaíam-se, entre outros, livros e cadernos de poesia editados de forma artesanal e distribuídos ou vendidos de mão em mão nas ruas, portas de teatros, cinemas, bares, shows e nas universidades. O importante era que chegassem ao público e contribuíssem para a divulgação de suas ideias, que abordavam temas diversos como a luta de classes, sexo e sexualidade, o uso de drogas e a política, marcando não somente uma preocupação com o historicismo de conteúdo crítico, mas também com a questão estética do que produziam.

Eram artistas que não se definiam por uma escola ou movimento específico de vanguarda e que procuravam aproveitar todas as fontes, desde o modernismo até a vanguarda concretista, o que faziam de maneira espontânea e intuitiva, sem se prender a amarras conceituais muito rígidas. O que eles queriam mesmo era poder se expressar livremente num período em que as coisas não estavam fáceis. O país passava pela fase de endurecimento do regime militar, após a decretação do Ato Institucional n 5 em 1968 e que determinou a perda de direitos políticos, a cassação de mandatos e a demissão de professores universitários tidos como subversivos, juntamente com a prisão, tortura e assassinato de dissidentes políticos, tudo isso somado a censura dos meios de comunicação.

Nesse período, ficou marcada a disputa entre os representantes da arte engajada do CPC (Centro Popular de Cultura) e os integrantes da Tropicália, defensores de uma arte sem compromissos diretamente expressos com a luta de classes e mais voltados para a preocupação estética o que, inclusive, os aproximou dos poetas concretistas. Ressalta-se que, segundo Hollanda ${ }^{22}$, o surgimento da Tropicália e o fortalecimento dos movimentos estudantis universitários na virada da década de 1960 para a década de 1970 introduzem novas temáticas na produção cultural do país: sexo, drogas, liberdade, juventude, feminismo e sexualidade, substituindo os temas do discurso crítico da luta de classes, típico das manifestações das vanguardas culturais da primeira metade dos anos sessenta, representadas, entre outros, pelo já citado CPC, e constituindo-se, dessa forma, uma nova vanguarda cultural brasileira.

Ao analisar a produção artística da Tropicália, $\mathrm{Schwarz}^{23}$, por sua vez, aponta para o uso que esse movimento fazia do discurso alegórico, em que ocorre a construção de uma

\footnotetext{
${ }^{22}$ HOLLANDA, Heloisa Buarque de. Impressões de viagem: CPC, vanguarda e desbunde: 1960/70. Rio de Janeiro: Aeroplano, 2004.

${ }^{23}$ SCHUARZ, Roberto. Cultura e Política. São Paulo: Paz e Terra, 2009.
} 
imagem absurda do país como um espaço em que as contradições entre o moderno e o arcaico acirravam-se devido ao processo de modernização do capitalismo, provocando a fixação de uma imagem estática e atemporal do Brasil, para a qual não haveria saída. Ainda de acordo com Hollanda ${ }^{24}$, esta visão, mesmo que bem adequada ao conceito benjaminiano de alegoria, colocaria essa produção sob a perspectiva crítica de Lukács que considerava a necessidade de uma perspectiva finalista para a obra de arte. Para Schwarz ${ }^{25}$, o discurso tropicalista era incapaz de demonstrar que as contradições da sociedade brasileira eram historicamente determináveis e, portanto, passíveis de serem superadas.

Em entrevista concedida à Hollanda ${ }^{26}$, na Faculdade de Letras da UFRJ, em outubro de 1978, José Celso Martinez Corrêa dizia que a crítica de Schwarz demonstrava a incapacidade do pensamento marxista tradicional de entender a linguagem de corpo que estava sendo falada pelos tropicalistas e que o erotismo, a subversão de valores e comportamentos apareciam como demonstração da insatisfação com um momento de permanência do regime ditatorial que promovia a inquietação, a dúvida e a crise da intelectualidade: "estávamos no Eros e na Esquerda!". ${ }^{27}$

A questão que se colocava neste debate era, portanto, se a produção artístico-literária deveria expor uma busca pela aproximação com a sociedade, priorizando o conteúdo historicista por meio do discurso direto voltado para as bases da sociedade, como propunha o CPC (Centro Popular de Cultura) e o fazia com vistas a uma revolução socialista ou nacionalpopular, ou pelo uso do discurso indireto, cuja ênfase seria a estética e o simbólico, empregado pela Tropicália, promovendo uma forma de guerrilha anárquica, que partiria da busca pela emancipação transformadora do indivíduo para, então, se chegar ao coletivo social por meio de sua ação, a partir do interior das estruturas da indústria cultural, mas sem que isso, necessariamente, tivesse como objetivo a tomada do poder. Ou seja, uma condição de desbunde quanto aos padrões comportamentais vigentes tanto na direita conservadora e retrógrada, quanto na esquerda revolucionária ancorada no discurso marxista-leninista. Ao analisar essa problemática em torno da sociologia da cultura e a interpretação da obra individual que marcou a produção artístico-literária dos anos 1960-1970, por meio de uma síntese do pensamento de Otto Maria Carpeaux e António Cândido, Bosi ${ }^{28}$ observa que

\footnotetext{
${ }^{24}$ Ibidem

${ }^{25}$ Ibidem

${ }^{26}$ HOLLANDA. Heloisa Buarque de. Impressões de viagem: CPC, vanguarda e desbunde: 1960/70. Rio de Janeiro: Aeroplano, 2004.

${ }^{27}$ Ibidem

${ }^{28}$ BOSI, Alfredo. Literatura e resistência. São Paulo: Companhia da Letras, 2002, pág. 29.
} 
nenhum dos métodos vigentes era capaz, em termos dialéticos, de solucionar sozinho o compromisso com uma criação estética individual e o processo social de uma nação colocado e situado em termos históricos.

Convém lembrar aqui, que, em 1978, a Secretaria Municipal de Cultura de São Paulo desenvolveu uma política cultural para a cidade que buscava identificar e "revitalizar" sítios históricos e/ou artísticos na periferia da cidade, visando a museíficação da cultura com base no pressuposto da inexistência de uma produção cultural viva e de qualidade nessas comunidades operárias de origem migrante. Aliás, Arantes ${ }^{29}$, refletindo sobre a concepção de arte e de cultura que embasava a proposta, assinalava: "Os que me convidavam a fazê-lo consideravam a área onde se localizava esse bem, [...] uma área culturalmente muito pobre, com uma produção local praticamente inexistente ou muito insignificante. [...]”. Porém, não foi preciso muito tempo para que o pesquisador lá encontrasse uma gama de experiências sociais diversificadas, contrariando concepções preestabelecidas do órgão responsável pela cultura da cidade, que subestimava as experiências pessoais e sociais dos moradores da periferia.

Nesse percurso, deparamo-nos com a pequena Capela Jesuítica de São Miguel Arcanjo, construída por volta de 1600, por padres jesuítas junto ao aldeamento indígena que se situava na margem esquerda do rio Tietê, à montante da Vila de São Paulo de Piratininga, considerada marco fundador do bairro São Miguel Paulista. À proposta desenvolvida em parceria entre a prefeitura da cidade e a igreja católica de transformar essa capela em museu de arte sacra jesuítica, opõe-se um grupo de artistas locais, que funda o MPA, Movimento Popular de Arte de São Miguel Paulista, apresentando um projeto cujo objetivo era transformar a pequena capela em um centro cultural em que promoveriam e divulgariam sua produção artístico-literária. O grupo alcança seu intento durante um breve período, de aproximadamente um ano, ocupando o interior da pequena capela, promovendo diversas formas de intervenção cultural, dentre as quais se destacaram as apresentações teatrais e musicais, os varais de poesia. Eram produções artísticas preocupadas com a denúncia das condições de vida da população local e, ao mesmo tempo, do momento político do país, ainda vivendo sob a repressão da ditadura civil-militar, ao mesmo tempo que buscavam fortalecer a identidade e o caráter de classe daquela comunidade.

A importância que esse movimento social representou para a cena cultural e política paulistana do final da década de 1970 e início da década de 1980 foi significativa, visto que as

\footnotetext{
${ }^{29}$ ARANTES, António Augusto. Produzindo o Passado. Estratégias de Construção do Patrimônio Cultural. São Paulo: Brasiliense, 1984, pág. 150.
} 
experiências ali vivenciadas contribuíram para uma melhor compreensão das formas de mobilização e reivindicação social da periferia das grandes cidades, tanto assim que, segundo Morais $^{30}$, faz-se necessário iluminar experiências como as do Movimento Popular de Arte (MPA), resistente à massificação e ao nivelamento da cultura popular. Essa necessidade, utilizando-nos das palavras de Bosi ${ }^{31}$ mostra que: "[...] empobrecedora para a nossa cultura é a cisão com a cultura do povo: não enxergamos que ela nos dá, agora, lições de resistência como nos mais duros momentos da história da luta de classe". Esse grupo, o MPA, em 2013, completou trinta e cinco anos de sua formação e, ao analisarmos sua trajetória, é possível perceber que a sua atuação foi de fundamental importância para que ficasse demonstrado que a periferia possui suas próprias formas de produção e resistência culturais sendo capaz, dessa forma, de construir e estabelecer sua própria identidade sócio espacial.

Vale lembrar o fato de São Miguel Paulista ser um bairro cuja origem remonta aos tempos da fundação do Pátio do Colégio e que recebeu imigrantes de origem europeia e asiática até o início do século XX, a partir dos anos 1930, passou a ser um dos distritos de maior crescimento populacional do município de São Paulo em virtude das migrações intrarregionais ocorridas no Brasil, como consequência do êxodo-rural. Entre os novos moradores do lugar destacam-se os paulistas e mineiros, trazidos das fábricas desses estados, pertencentes aos proprietários da Companhia Nitro Química, para exercer cargos de chefia, e os nordestinos contratados para exercerem as funções braçais da produção.

Nesta composição demográfica tão diversa não tardaram a aparecer as questões relativas a segregação socioespacial entre seus moradores. A Vila Operária do lado direito da linha férrea, que abrigava os trabalhadores braçais da fábrica, e a Vila Nitro que abrigava os trabalhadores de nível técnico e gerencial do seu lado esquerdo, são demonstrações desse fenômeno geográfico, também o debate que se deu nos anos 1930/1940 em torno do nome do bairro, que chegou a ser Baquirivu, em referências as suas remontas origens indígenas, mas, poderia ter sido São Miguel dos Baianos, referência aos nordestinos, e acabou São Miguel Paulista, marcando a identidade bandeirante. E quanto a isso, também as mudanças de nomes dos lugares, como foi o caso da histórica estrada do Lageado que acabou rebatizada avenida Nordestina, são demonstrações das disputas socioidentitárias pelo espaço da cidade.

\footnotetext{
${ }^{30}$ MORAIS. Isabel Rodrigues de. São Miguel Paulista - Capela de São Miguel Arcanjo: Interfaces da Memória do Patrimônio Cultural. Dissertação de Mestrado - Pontifícia Universidade Católica de São Paulo. São Paulo, 2007, pág. 43.

${ }^{31}$ BOSI, Ecléa. Problemas ligados à cultura das classes populares. In VALLE, Edênia e QUEIROZ José (orgs). A cultura do povo. São Paulo: Educ, 1982, pág. 23.
} 
Após serem obrigados a desocupar a capela, os artistas passaram a ocupar a Praça Padre Aleixo Mafra, onde a mesma se localiza e, partir daí, as intervenções culturais feitas, geralmente aos domingos passaram a ser encerradas sempre com um grande baile de forró e o local passou a ser conhecido também como Praça do Forró.

Cartaz de divulgação do baile de forró realizado na Praça

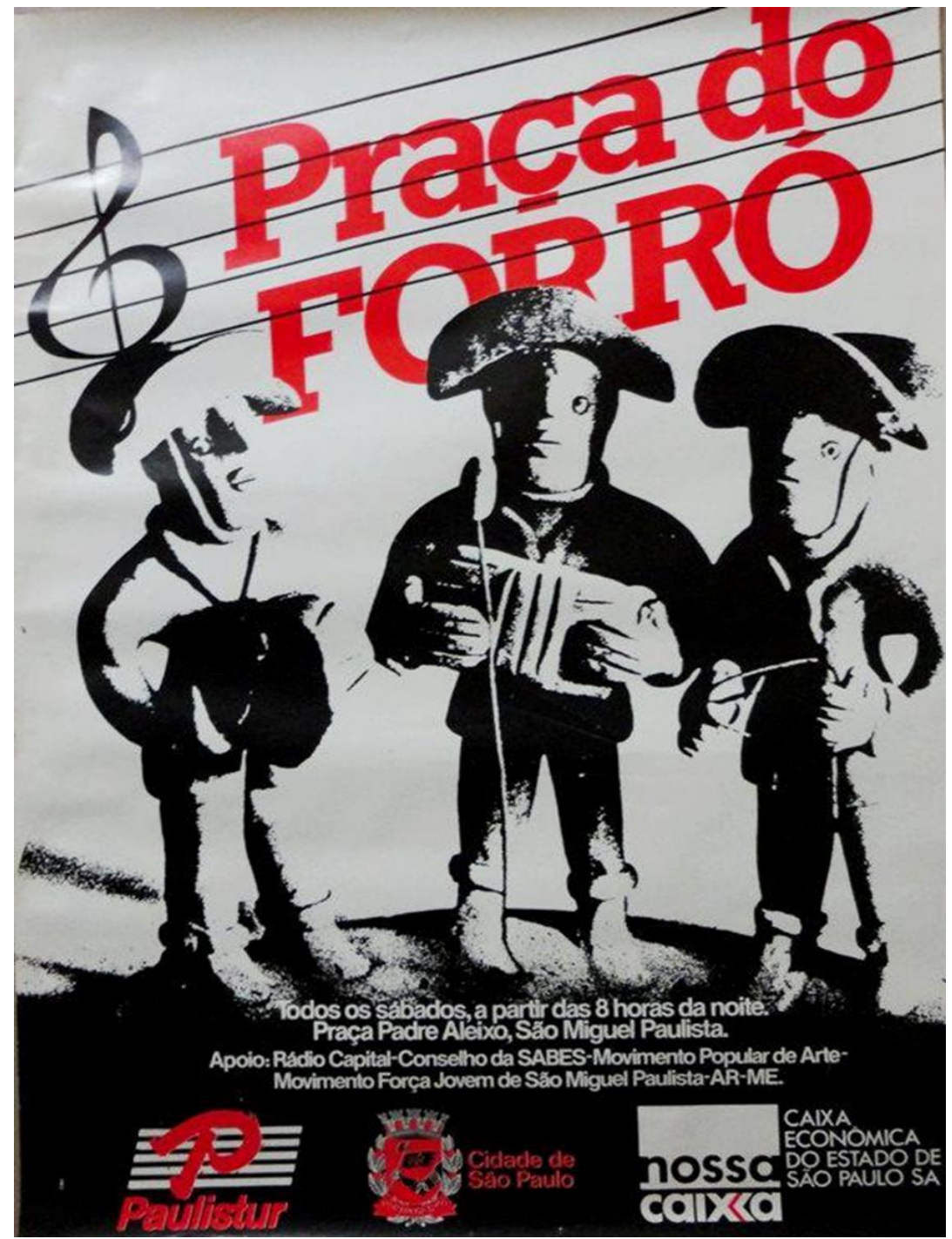

Se estabelece, desde então, uma certa dificuldade em torno das formas de identificação do local, aquela que remete ao caráter religioso dos tempos iniciais da colonização e aquela que aponta para a formação de uma nova comunidade de origem migrante refletindo, ainda hoje, o conflito entre as diferentes maneiras de interpretação do valor simbólico e identitário do espaço da cidade pelos diversos grupos sociais que dele fazem uso. Nada mais significativo do que o fato de se tratar de uma praça, pois, a praça é o espaço da cidade que

\section{Fistotorias}


representa seu valor de uso, a cidade que luta para permanecer livre do julgo da mercadoria e que, ao longo das décadas que se seguiram ao final dos anos 1970, vem lutando contra as estratégias de gentrificação urbana que segundo Harvey ${ }^{32}$, consistem nas estratégias de absorção do excedente por meio da transformação urbana que implica uma grande recorrência de reestruturação urbana por meio da "destruição criativa" marcadas pelo urbanismo em que o mapa precede a realidade ou, ainda, pelo urbanismo inocente de certos urbanistas que acabam, por fim, servindo aos interesses do capital e suas necessidades de reprodução.

Folheto de divulgação de programação do Movimento Popular de Arte

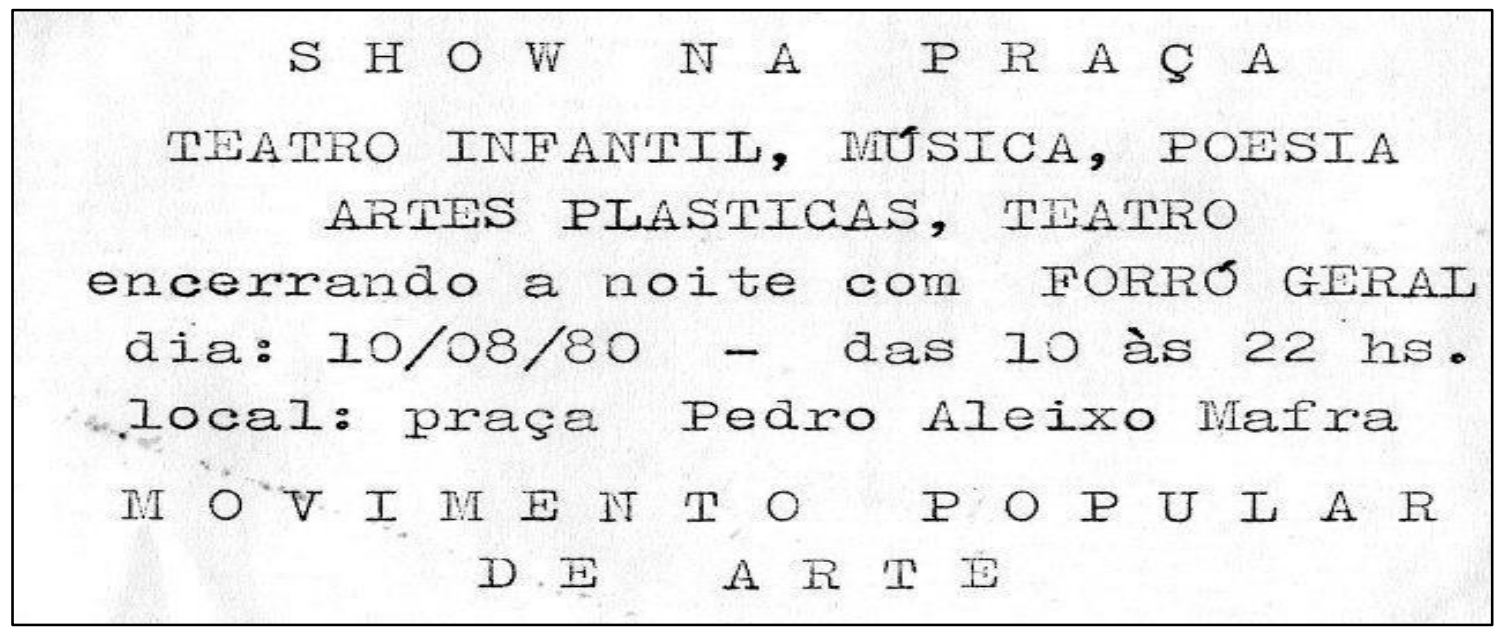

As produções artísticas do grupo tiveram a preocupação de denunciar as condições de vida da população local e, ao mesmo tempo, o momento político do país, ainda vivendo sob a repressão da ditadura militar. Em seus manifestos as vanguardas sempre procuram estabelecer seus princípios metodológicos, e suas aspirações quanto ao papel da arte na sociedade, e o manifesto de apresentação do Movimento Popular de Arte de São Miguel Paulista, não foi diferente. Deixando clara a intenção de promover uma produção artística engajada

\footnotetext{
${ }^{32}$ HARVEY, David. Cidades rebeldes: do direito à cidade à revolução urbana. São Paulo: Martins Fontes- selo Martins, 2014, p. 49.
} 
Manifesto de apresentação do Movimento Popular de Arte

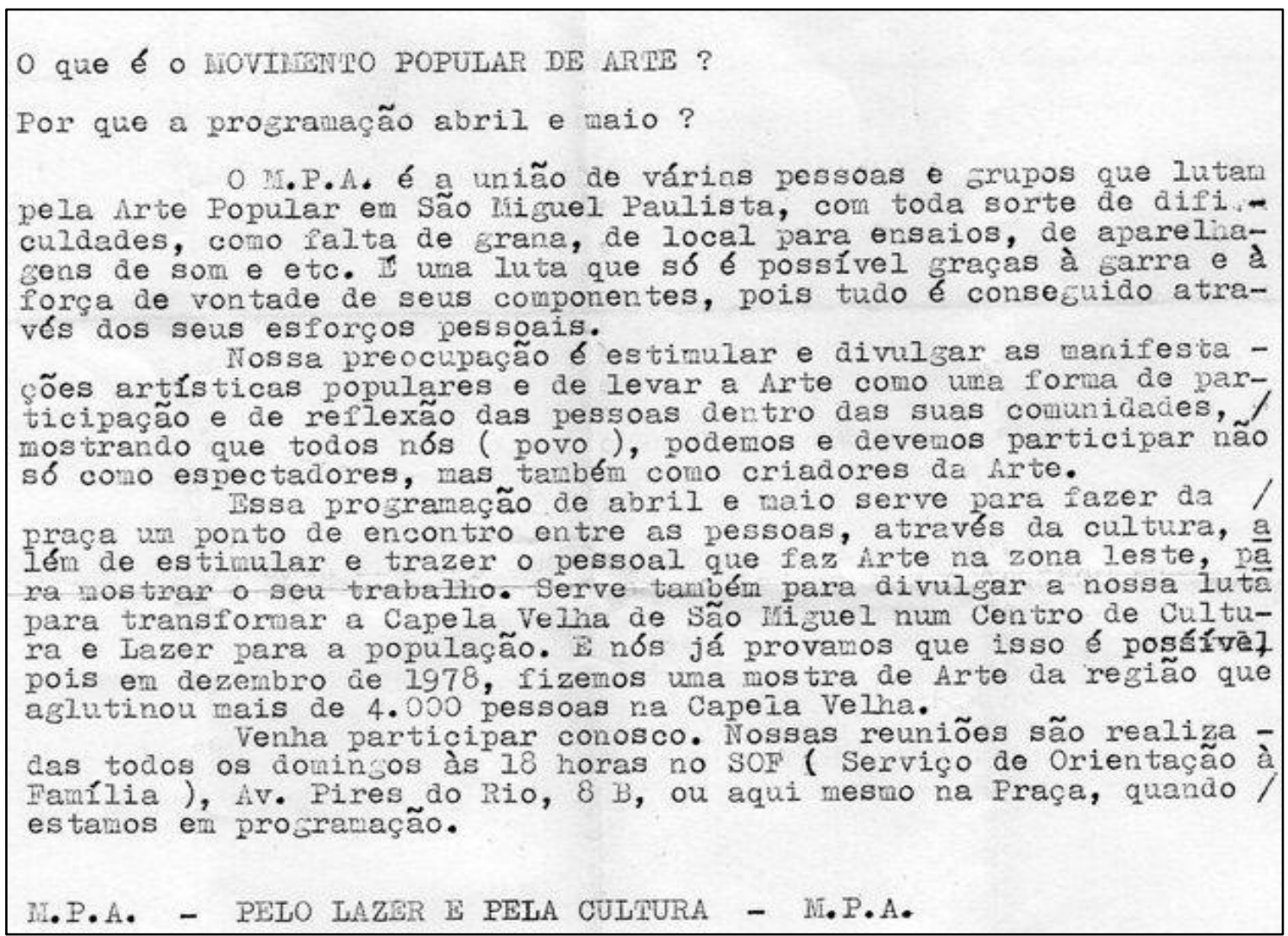

Tendo em vista o significado e a importância que esse movimento social representou para a cena cultural e política paulistana do final da década de 1970 e início da de 1980, assim como por acreditar que as experiências ali vivenciadas podem contribuir para uma melhor compreensão das atuais formas de mobilização e reivindicação social, alguns pesquisadores têm se debruçado sobre ele.

Além disso, segundo Morais (2010, ed. 43), é necessário iluminar experiências como o Movimento Popular de Arte (MPA), cujo objetivo inicial era o de encontrar uma forma de revitalizar a Capela de São Miguel Arcanjo, resistindo à massificação e ao nivelamento da cultura popular. 
Manifesto político sobre as eleições de 1982 do Movimento Popular de Arte

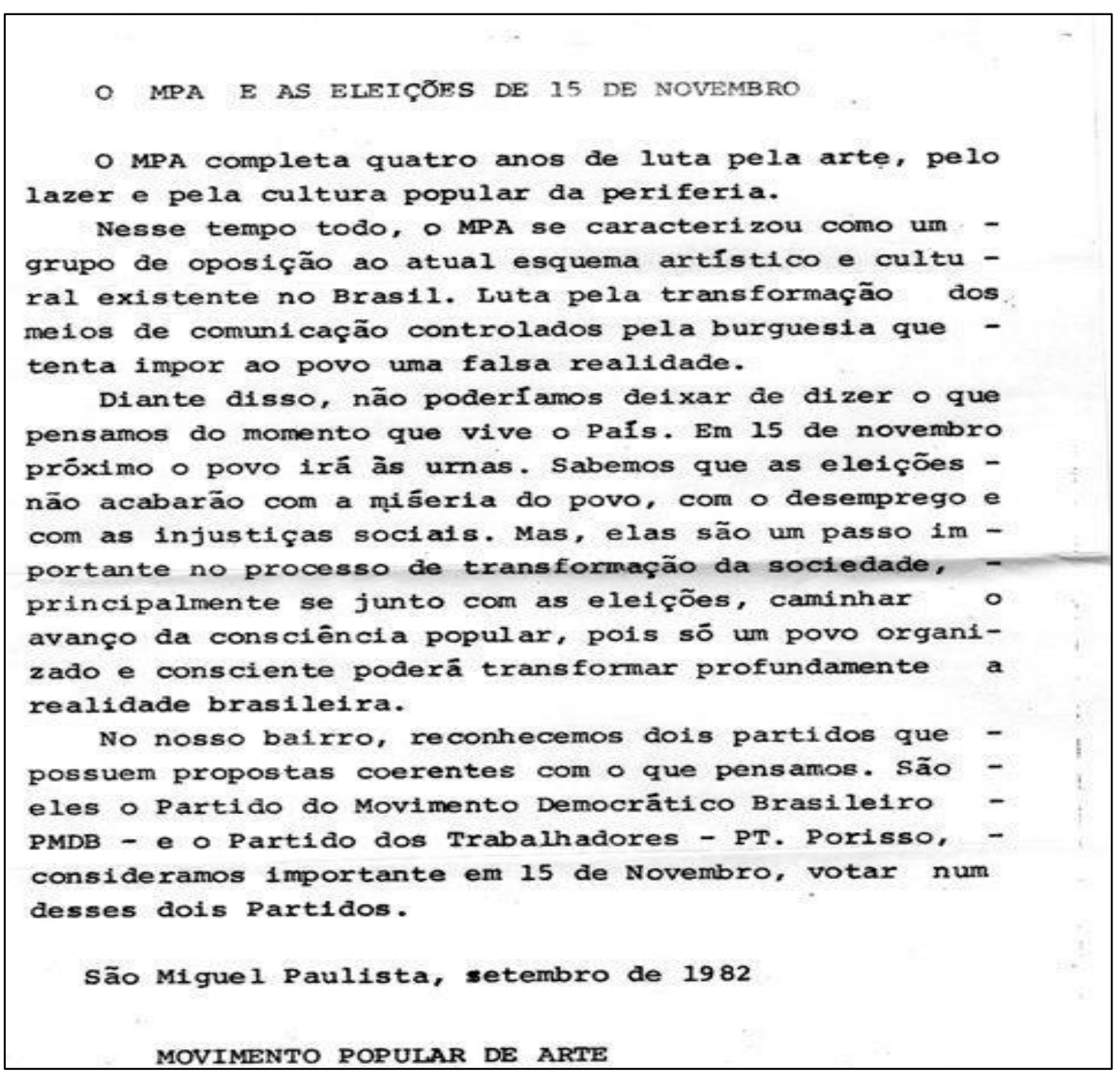

Segundo Sposito ${ }^{33}$, a relação entre arte e política, movimentos populares e Estado, cultura de massas e cultura popular é um importante aspecto a ser explorado naquilo que diz respeito a produção do MPA - Movimento Popular de Arte de São Miguel Paulista. Uma das fontes documentais mais significativas do acervo do Movimento, para a identificação do teor político da sua produção artístico-literária, são os cadernos de poesia que foram editados entre 1979 e 1985, contendo obras dos diferentes artistas que dele fizeram parte.

\footnotetext{
${ }^{33}$ SPOSITO (Coord.), Marília Pontes. Memória do Movimento Popular de Arte no Bairro de São Miguel: cultura, arte e educação. São Paulo. Universidade de São Paulo - Faculdade de Educação - Departamento de Filosofia da Educação e Ciências da Educação - Núcleo de Estudos de Sociologia da Educação, 1987, p. 3.
} 
Poema n ${ }^{\circ} 6$ - Sexto Caderno de Poesias - Movimento Popular de Arte

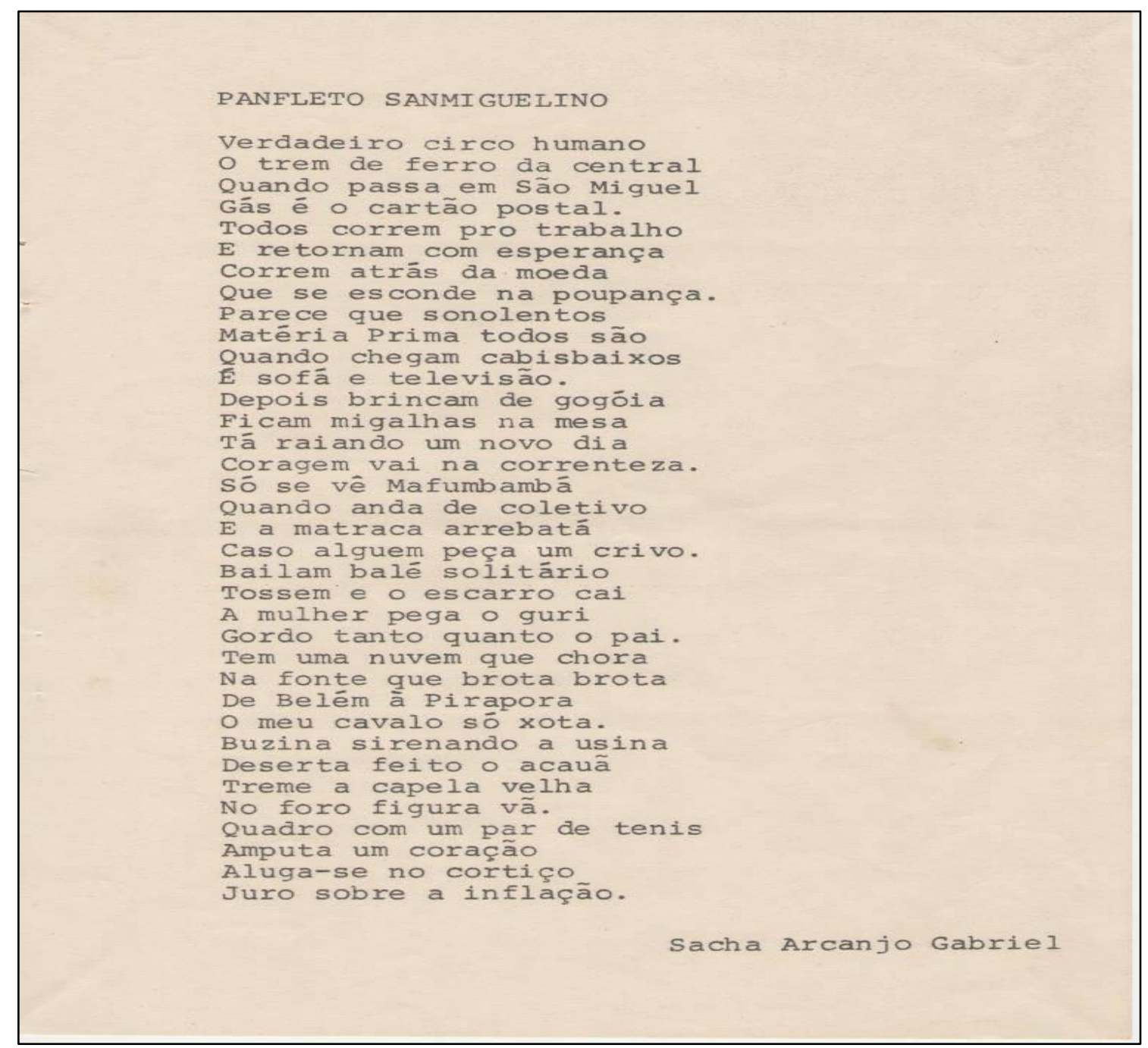

Elas trazem aspectos do cotidiano, contendo não somente a percepção quanto ao serestar espacial de cada um naquela realidade em que se inserem mas, também, aspectos sociais que representam e denunciam as carências e reivindicações da comunidade, próprias de uma estrutura econômica caracterizada pela urbanização enquanto processo de valorização seletiva e rentista do espaço da cidade.

Aos movimentos sociais do período 1960-1980, seguiu-se um discurso midiáticocorporativo-estatal bem articulado, que conseguiu absorver e transformar os protestos em meras manifestações representativas dos direitos civis das minorias, não permitindo que houvesse uma discussão mais profunda sobre a crise do capitalismo. Formou-se um discurso ideológico de caráter conservador ensurdecedor que fez com que as vozes de protesto fossem 
baixando até que não pudessem ser ouvidas. Acontece que, como afirma Reguillo ${ }^{34}$, os "xamans" do mercado estavam errados, e as questões sociais foram se avolumando e o entendimento acerca do que significava ser proletário, jovem e pobre, foi avançando na medida em que a corporação Estado-Capital foi se deixando mostrar por intermédio das políticas.

Observadas as especificidades históricas de cada momento, sem deixar de considerar suas semelhanças, cumpre lembrar que, nos últimos anos, percebemos a ocorrência de uma série de protestos exigindo mais democracia e transparência no sentido de uma maior participação popular na tomada de decisões, tanto no âmbito local quanto nacional dos governos, consequência do uso corporativo do Estado pelas grandes empresas e pelos grupos organizados de poder, colocando em questão o modelo de democracia representativa, o discurso da racionalidade econômica e as políticas governamentais calcadas na lógica da contenção de gastos públicos e na eficiência dos mercados.

Os protestos populares que vêm ocorrendo desde 2008, em diferentes lugares do mundo, em países árabes do Norte da África e do Oriente Médio, que acabaram denominados como a "Primavera Árabe"; nos Estados Unidos, como o movimento "Ocupa Wall Street"; na Europa, os protestos contra as políticas de combate à crise fiscal definidas pela "Troica", e as manifestações brasileiras, em muito remetem ao ambiente vivido no mundo entre 1960 e 1980. Nos dois momentos, trata-se de movimentos sociais de caráter urbano que refletem não apenas uma crise estrutural cíclica de reprodução do capital, mas, um questionamento sobre valores e princípios sociais, sobretudo naquilo que envolve a relação entre o que representa o público e o privado, o desenvolvimento dos meios de comunicação e a expansão quantitativa e qualitativa das classes médias urbanas.

Como a insatisfação popular em relação ao modo de governar, baseado na racionalidade econômica e na concessão de privilégios fiscais e monetários aos conglomerados transnacionais, vai se tornando evidente, a única resposta encontrada pelos governos vincula-se à repressão policial sobre o direito de uso e ocupação do espaço urbano. Essa resposta vem ao encontro do processo de gentrificação urbana adotado pelos governos atuais, na tentativa de formular novas estratégias de segregação e controle social sobre a

\footnotetext{
${ }^{34}$ REGUILLO, Rossana. Utopias e Heterotopias Urbanas. A disputa pela cidade possível. In: SERRA, Monica Allende (org.). Diversidade Cultural e Desenvolvimento Urbano. São Paulo: Iluminuras, 2005, p.199.
} 
cidade, com base na concepção da recuperação de áreas urbanas degradadas e da necessidade de ampliação das estratégias de segurança pública, como postula Carlos ${ }^{35}$.

\section{Referências Bibliográficas}

AB' SABER, Aziz Nacib. O sítio urbano de São Paulo in AZEVEDO, Aroldo. A cidade de São Paulo, Estudos de Geografia Urbana. São Paulo: Editora Nacional, 1958, vol. 1

ARANTES, Antonio Augusto. Produzindo o Passado. Estratégias de Construção do Patrimônio Cultural. São Paulo: Brasiliense, 1984.

AZEVEDO, Aroldo de. Subúrbios Orientais de São Paulo. São Paulo: USP, Doutorado em Geografia, 1945.

BASTIDE. Roger. Brasil, Terra de Contrastes. São Paulo: Difel, 1978.

BENJAMIN, Walter. Rua de mão única. Obras Escolhidas II, São Paulo: Editora Brasiliense, 1987.

BERMAN, Marshal. Tudo que é Sólido se Desmancha no Ar - A Aventura da Modernidade, São Paulo: Cia. das Letras, 1986.

BOMTEMPI, Sylvio. O Bairro de São Miguel Paulista. São Paulo: Prefeitura Municipal/Departamento de Cultura, 1970.

. Origens Históricas de São Miguel Paulista. São Paulo: Unicsul, 2000. BOSI, Alfredo. Literatura e resistência. São Paulo: Companhia da Letras, 2002.

BOSI, Ecléa. Problemas ligados à cultura das classes trabalhadoras. In VALLE e QUEIROZ (Orgs). A cultura do povo. São Paulo: Educ, 1982.

BRESCIANI, Maria Stella. Permanência e Ruptura no Estudo das Cidades. Texto Xerografado, 1990 in LANNA, Ana Lúcia Duarte. Uma Cidade na Transição, Santos: 1870-1913. São Paulo-Santos: Editora Hucitec - Prefeitura Municipal de Santos, 1996.

CANCLINI, Néstor García. O Papel da Cultura em Cidades pouco Sustentáveis. In SERRA, Monica Allende. Diversidade Cultural e Desenvolvimento Urbano. São Paulo: Iluminuras, 2005.

CARLOS, Ana Fani Alessandri. A cidade. São Paulo: Editora Contexto, 2007.

DEAN, Warren. A Industrialização de São Paulo (1880-1945). Tradução São Paulo: Difel, 1971.

FONTES, Paulo Roberto Ribeiro. Comunidade Operária, Migração Nordestina e Lutas Sociais: São Miguel Paulista (1945-1966). Campinas: Universidade Estadual de Campinas, 2002.

GEORGE, Pierre. La ville. Le fait urban a travers le monde, 1952. In LANNA, Ana Lúcia Duarte. Uma Cidade em Transição, Santos: 1870-1913. São Paulo - Santos: Editora Hucitec - Prefeitura Municipal de Santos.

GOULART REIS FILHO, Nestor. Evolução Urbana do Brasil. São Paulo: Pioneira, 1968 in SANTOS, Milton. A Urbanização Brasileira. São Paulo: Editora da Universidade de São Paulo, 2009.

HOBSBAWN, Eric. A Era do Capital, 1848-1875. Tradução Rio de Janeiro: Paz e Terra, 1982.

A Era dos Impérios. Tradução Rio de Janeiro: Paz e Terra, 1988. HOLLANDA, Heloísa Buarque de. Impressões de viagem: CPC, vanguarda e desbunde: 1960/70. Rio de Janeiro: Aeroplano, 2004.

JACOBS, Janes. Morte e Vida de Grandes Cidades. Coleção Mundo da Arte. São Paulo: Editora WMF Martins Fontes Ltda, 2009

JORGE, Janes. Tietê, o rio que a cidade perdeu: São Paulo 1890-1940. São Paulo: Alameda, 2006.

LANNA, Ana Lúcia Duarte. Uma Cidade na Transição, Santos: 1870-1913. São Paulo-Santos: Editora Hucitec - Prefeitura Municipal de Santos, 1996.

LEFEBVRE, Henri. O Direito à Cidade. São Paulo: Documentos, 1969.

\footnotetext{
${ }^{35}$ CARLOS, Ana Fani Alessandri. A cidade. São Paulo: Editora Contexto, 2007, p. 84-85.
}

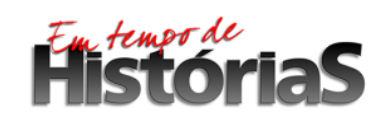


MORAIS, Isabel Rodrigues de. São Miguel Paulista - Capela de São Miguel Arcanjo: Interfaces da Memória do Patrimônio Cultural. Dissertação de Mestrado - Pontifícia Universidade Católica de São Paulo. São Paulo, 2007.

POGLIOLI, Renato. Teoria de la arte de vanguarda.Madri: Revista de Occidente, 1964.

REGUILlO, Rossana. Utopias e Heterotopias Urbanas. A disputa pela cidade possível. in SERRA, Monica Allende (org.). Diversidade Cultural e Desenvolvimento Urbano. São Paulo: Iluminuras, 2005.

RIBEIRO, Darcy. O Processo Civilizatório. Rio de Janeiro: Civilização Brasileira, 1975.

SANTOS, Milton. A Urbanização Brasileira. São Paulo: Editora da Universidade de São Paulo, 2009.

SCHUARZ, Roberto. Cultura e Política. São Paulo: Paz e Terra, 2009.

SILVA. Maria Aparecida de Moraes. Errantes do fim do século. São Paulo: Editora Unesp, 1999.

SINGER, Paul. A formação da classe operária. Campinas: Editora da Universidade Estadual de Campinas, 1987.

SPOSITO, Marília Pontes (coord.). Memória do Movimento Popular de Arte no Bairro de São Miguel Paulista: Cultura, Arte e Educação. USP, FFCL, 1987.

WILliANS, Raymond. O Campo e a Cidade. Trad. São Paulo: Cia. das Letras, 1989. 